Rev. Bras. Saúde Prod. Anim., Salvador, v.17, n.4, p.642-651 out./dez., 2016 http://www.rbspa.ufba.br ISSN 15199940

\title{
Uso de modelos de regressão logística para avaliar a composição físico-química do leite bovino in natura
}

\author{
Logistic regression models for evaluation of physico-chemical composition of bovine \\ milk "in natura"
}

\author{
TORRES, Haendel Alexandre Lopes ${ }^{1}$; RAIDAN, Fernanda Santos Silva ${ }^{2}$; \\ ALMEIDA, Anna Christina de ${ }^{1 *}$; MORÃO; Rodrigo Pereira ${ }^{1}$; VIEIRA, Isabella \\ Luiza Nascimento Lopes ${ }^{1}$; OLIVEIRA, Stephanie Pedrosa de ${ }^{1}$
}

\author{
${ }^{1}$ Universidade Federal de Minas Gerais, Instituto de Ciências Agrárias, Montes Claros, Minas \\ Gerais, Brasil. \\ ${ }^{2}$ Universidade Federal de Minas Gerais, Escola de Veterinária, Departamento de Zootecnia, Belo \\ Horizonte, Minas Gerais, Brasil. \\ *Endereço para correspondência: annachristinadealmeida@gmail.com
}

\section{RESUMO}

Objetivou-se avaliar, por meio de regressão logística, a relação entre composição físico-química do leite in natura e probabilidade de ocorrência de mastite em fềmeas mestiças Holandês, Gir e Jersey. O resultado do teste de CMT (positivo=1 e negativo=0) foi utilizado para estudo da probabilidade de ocorrência de mastite que foi modelada por meio de regressão logística. O modelo final composto por teor de gordura, lactose e contagem de células somáticas (CCS) foi escolhido por meio do procedimento Stepwise, disponível em SAS ${ }^{\circledR}$, a partir das variáveis regressoras fazenda, teores de proteína, extrato seco desengordurado (ESD), gordura, lactose, e CCS. Observou-se que 53,86\% dos animais apresentaram mastite subclínica. As variáveis CCS e teores de gordura e lactose influenciaram a probabilidade de ocorrência de mastite e incrementos de uma unidade de CCS, gordura e lactose possibilitam aumento de $0,4 \%$ e $52,8 \%$ e redução de $96,5 \%$, respectivamente na probabilidade de ocorrência de mastite. A contagem de célula somática é a variável de maior impacto sendo que 600.000 células $/ \mathrm{mL}$ resulta em $28 \%$ de probabilidade de ocorrência de mastite. O modelo de regressão logística permitiu quantificar o impacto da presença de mastite no rebanho e a composição físico-química do leite in natura.

Palavras-chave: bovinocultura leiteira, 'California Mastitis Test', qualidade do leite

\section{SUMMARY}

This study aimed to evaluation, through logistic regression model, the relationship between physical-chemistry composition of bovine milk in natura and probability of occurrence of mastitis in crossbred female cattle from Hostein, Gyr and Jersey breed. The result of the CMT (positive $=1$ and negative $=0$ ) was used to study the probability of occurrence of mastitis that was modeled using logistic regression. The final model consists of fat, lactose and somatic cell count (SCC) was selected by the Stepwise procedure available in $\mathrm{SAS}^{\circledR}$, from the regressive variables farm, protein, degreased dry extract, fat, lactose, and SCC. It was observed that $53.86 \%$ of the animals had subclinical mastitis. The CCS, fat and lactose influenced the probability of incidence of mastitis and an increase in one unit of these variables is associated with an increase of $0.4 \%$ and $52.8 \%$ and reduction of $96.5 \%$, respectively in the probability of incidence of mastitis. The CCS is the variable with the greatest impact on probability of mastitis, and the count of 600.000 cells $/ \mathrm{mL}$ result in the $28 \%$ of probability of incidence of mastitis. The logistic regression model to quantify the impact from mastitis in the physical-chemistry composition of milk in natura in the dairy herd.

Keywords: 'California Mastitis Test', dairy cattle, milk quality 


\section{INTRODUÇÃO}

A mastite bovina é resultado de processos inflamatórios desencadeados pela ação das células de defesa sobre os patógenos presentes no interior da glândula mamaria dos animais. Essa enfermidade pode apresentar-se na forma clínica, com edema do úbere, aspecto febril e dor a palpação, ou subclínica, caracterizada pelo aumento das células somáticas (CCS) e alterações na composição físico-química e microbiológica do leite (PHILPOT \& NICKERSON, 1991; RADOSTITS, 2002).

Alternativa usual para diagnóstico da mastite subclínica, que apresenta maior prevalência entre os rebanhos leiteiros nacionais, é o 'California Mastite Teste' (CMT, ZAFALON et al., 2009). Após o diagnóstico da mastite o desenvolvimento e aplicação de diferentes medidas de controle e das boas práticas de higiene durante a ordenha podem auxiliar a cadeia produtiva do leite aumentar a produção total e a qualidade do leite produzido. Assim, melhorias no manejo sanitário e nutricional e uso de reprodutores geneticamente superiores para produção e qualidade do leite são alternativas para aumentar $o$ retorno econômico em sistema de produção de leite (VLIEGHER et al., 2012). O aumento no teor de sólidos do leite pode ser estimulado por políticas de pagamento por qualidade. Além disso, a composição genética dos animais altera a composição do leite e a heterose, presente em animais cruzados, pode contribuir para incremento nas concentrações de sólidos (DEZETTER et al., 2015). Deste modo, o conhecimento dos fatores que influenciam a produção e a composição do leite é preponderante para o sucesso da empresa rural produtora de leite (ARAÚJO et al., 2011; VLIEGHER et al., 2012). A influência da mastite na composição físico-química do leite bovino in natura está bem documentada na literatura (PEREIRA et al., 1999; NIELSEN et al., 2005; ARAÚJO et al.,
2011; RANGEL et al., 2013, REIS et al., 2013, GONÇALVES et al., 2016). Contudo, a relação entre composição físicoquímica do leite e probabilidade de ocorrência de mastite não foi quantificada. Nesse sentido, objetivou-se com este trabalho avaliar por meio de modelos de regressão logística, a relação entre teores de proteína, extrato seco desengordurado (ESD), gordura, lactose e contagem de células somáticas (CCS) no leite bovino in natura e a probabilidade de ocorrência de mastite de fêmeas bovinas mestiças Holandês, Gir e Jersey.

\section{MATERIAL E MÉTODOS}

Um experimento com 184 fêmeas bovinas de diferentes composições genéticas foi realizado em três propriedades participantes do Programa de Extensão: Assistência Técnica a Agricultores Familiares em Atividades de Higiene, Produção e Saúde Pública do Instituto de Ciências Agrárias da Universidade Federal de Minas Gerais (ICA/UFMG). Duas propriedades estão localizadas no município de Bocaiuva e uma em Francisco Sá, tais propriedades não empregavam o correto manejo de boas práticas na ordenha, não levando em consideração o histórico de cada animal para a tomada de decisões, sendo assim, tal trabalho é pioneiro na avaliação da mastite na região.

Essas regiões de cerrado são caracterizadas por clima semiárido, com duas estações bem definidas: chuvosa, de outubro a março, e seca, de abril a setembro. A precipitação anual varia de 600 a $1.400 \mathrm{~mm}$ por ano, com chuvas concentradas de novembro a janeiro. A temperatura oscila entre 18 e $33^{\circ} \mathrm{C}$ (MELLO et al., 2007).

Os rebanhos caracterizaram-se por bovinos mestiços azebuados, com diversas composições genéticas das raças 
Holandês, Gir e Jersey, com idade mínima de 36 meses e em diferentes fases de lactação. As empresas rurais não mantinham arquivos zootécnicos com histórico de mastite ou dados produtivos em data anterior a participação no experimento. $\mathrm{O}$ manejo alimentar no período de estiagem, os animais eram mantidos em sistema semiextensivo, com uso de silagem de sorgo e cana-de-açúcar com ureia. As pastagens eram compostas por Brachiaria decumbens, Andropogon gayanus, Brachiaria brizantha e alguns cultivares de Panicum maximum (Colonião, Mombaça e Tanzânia).

Duas das propriedades realizavam ordenha mecânica com bezerro ao pé e protocolo para higienização dos tetos e dos equipamentos utilizados na ordenha entretanto, não era realizado pós dipping, uma vez que, após a ordenha os bezerros ficavam na presença das vacas até $o$ término da ordenha. A última propriedade realizava ordenha sem a presença de bezerros, sendo estes criados em casinhas com o fornecimento de leite natural em baldes individuais. Alem disso, empregava-se protocolo de boas práticas de higienização, com pré e pós dipping.

Em todos os rebanhos, após a ordenha, para avaliar a composição química e a CCS, foram coletados $40 \mathrm{ml}$ de leite, em frascos plásticos esterilizados $(80 \mathrm{x}$ $30 \mathrm{~mm}$ ) adicionados de conservante Bronopol ${ }^{\circledR}$ (2-bromo-2nitropropane-1,3- diol). Em seguida, as amostras foram acondicionadas em caixas isotérmicas e encaminhadas ao Laboratório de Análise da Qualidade do Leite da Universidade Federal de Minas Gerais para análise da composição do leite.

A contagem de células somáticas foi realizada em equipamento eletrônico Bentley CombiSystem $2300^{\circledR}$ da Bentley Instruments Incorporated $^{\circledR}$ (BENTLEY, 1997) pelo método de citometria de fluxo (INTERNATIONAL DAIRY FEDERATION, 1995). Já a análise da composição (teores percentuais de gordura, proteína, lactose e extrato seco desengordurado) foi realizada por absorção infravermelha, utilizando o equipamento Bentley Combi System $2300^{\circledR}$, conforme metodologia utilizada por Cunha et al. (2013).

Os dados foram submetidos aos testes de Liliefors e Bartlett, para verificar a normalidade dos erros e a homogeneidade das variâncias. Por não satisfazer aos mesmos, a CCS foi transformada pela função logarítmica de base 10. Os dados transformados atendiam as exigências de homogeneidade de distribuição dos resíduos. O resultado do teste de CMT (positivo $=0$ e negativo $=1$ ) foi utilizado para estudo da probabilidade de ocorrência de mastite que foi modelada por meio de regressão logística, considerando-se o seguinte modelo geral:

$$
\ln \left(\frac{p_{i j k l m n o}}{1-p_{i j k l m n o}}\right)=\beta_{0}+\beta_{1} x_{1 i}+\beta_{2} x_{2 j}+\beta_{3} x_{3 k}+\beta_{4} x_{4 l}+\beta_{5} x_{5 m}+\beta_{6} x_{6 n}+\varepsilon_{i j k l m n o}
$$

em que $p_{i j k l m n o}$ é a probabilidade de ocorrência de mastite do animal $n$, com CCS $i\left(x_{1 i}\right)$, teor de gordura $j\left(x_{2 j}\right)$, teor de proteína $k\left(x_{3 k}\right)$, teor de lactose $l\left(x_{4 l}\right)$, teor de ESD $m\left(x_{5 m}\right)$ e pertencente a fazenda $n\left(x_{6 n}\right) ; \beta_{0}$ é uma constante geral presente em todas as observações; $\beta_{h}$ $(h=1,2,3,4,5$ e 6) são os coeficientes de regressão associados as variáveis regressoras $X_{h}$; e $\varepsilon_{i j k l m n o}$ é o erro aleatório associado a cada observação.

As estimativas dos parâmetros $\left(\hat{\beta}_{h}\right)$ foram obtidas pelo método da máxima verossimilhança e o modelo final foi escolhido por meio da opção Stepwise do procedimento Logistic do Statistical Analysis System - SAS ${ }^{\circledR}$. As diferenças entre fazendas foram consideradas no modelo por meio do efeito fixo de 
fazenda, todos os animais empregados no estudo eram vacas adultas com mais de 2 lactações, não possuindo a informação de idade das mesmas.

Inicialmente, a opção Stepwise identifica a variável regressora que, isoladamente, proporciona o melhor ajuste. Em seguida, a outra variável que resulta no modelo de melhor ajuste com duas variáveis é incluída. A significância dos coeficientes de regressão é considerada para avaliar a necessidade de exclusão de alguma variável. Estes passos (inclusão de nova variável, avaliação da significância, necessidade de exclusão de variáveis) são repetidos até não haver mais variáveis para serem adicionadas ou excluídas do modelo (FREUND \& LITTELL, 2000).

\section{A odds ratio $\left(\frac{p(\text { sucesso })}{p(\text { insucesso })}\right)$ associada a cada variável regressora foi estimada}

por meio de $e^{\hat{\beta}_{h}}$ e define a mudança na odds ratio quando houver alteração de uma unidade da variável regressora (FREUND \& LITTELL, 2000).

A estatística utilizada para aferir a validade dos modelos foi a porcentagem de pares de observações-predições concordantes. Esse procedimento consiste em comparar as probabilidades entre as respostas observadas e preditas considerando todos os possíveis pares de observações $\left(y_{i}, y_{j}\right.$ onde $\left.i \neq j\right)$, de modo que as respostas observadas para $y_{i}$ 's sejam iguais a um (positivo) e as observadas para $y_{j}$ 's sejam iguais a zero (negativo). Dessa forma, houve a formação de $n_{i} \times n_{j}$ pares de observações (positivo $\mathrm{x}$ negativo no teste de CMT) que foram classificados em concordantes quando $\hat{P}_{i}>\hat{P}_{j}$, discordante quando $\hat{P}_{i}<\hat{P}_{j}$, e empatados se $\hat{P}_{i}>\hat{P}_{j}$. A proporção para cada modelo foi calculada em relação ao total de pares $n_{i} \times n_{j} \quad$ (BERGMANN \& HOHENBOKEN, 1992).

O nível de significância para os efeitos de qualidade do leite foi calculado pelo teste da razão de verossimilhança, que consiste da comparação entre o valor da função de verossimilhança obtida no modelo reduzido, que considera apenas a constante, e o valor da função no modelo completo, que inclui a variável regressora além do intercepto.
Para facilitar a interpretação dos efeitos de cada variável regressora incluída no modelo final separadamente foram construídos gráficos a partir dos valores de $\hat{\beta}_{h}$ mantendo-se $x_{h}=\bar{x}_{h}$ e variando-o dentro da amplitude observada para a variável regressora de interesse.

\section{RESULTADOS E DISCUSSÃO}

Observou-se que $53,86 \%$ dos animais apresentaram mastite subclínica. Fatores como temperatura ambiental, condições anti-higiênicas dos estábulos, manejo incorreto dos animais e nutrição desbalanceada podem explicar alta prevalência de mastite nos rebanhos avaliados (FERREIRA et al., 2007; ROMA JÚNIOR et al., 2009).

$\mathrm{O}$ maior coeficiente de variação $(\mathrm{CV})$ foi observado para CCS (CV = 119,60\%). A variação observada pode estar relacionada aos fatores genéticos e ambientais como alimentação, intervalos entre ordenhas, estágios de lactação (Tabela 1). Isso reforça a importância de desenvolver e implantar estratégias de manejo para reduzir as vias de transmissão de mastite. A implantação do programa de qualidade do leite, com a finalidade de obter um produto em condições higiênicas sanitárias adequadas, ou seja, livres de agentes contaminantes, utilização do teste CMT (Califórnia Mastitis Tests), desinfecção dos animais antes e após a 
ordenha, e sanitização dos utensílios e equipamentos da ordenha são alternativas eficientes para redução da CCS (SCABIN et al., 2012).

$\mathrm{Na}$ Nova Zelândia, Austrália e União Européia, desde o ano de 2000, foram estabelecidas limites de CCS de 400.000 células/ml para leite in natura de espécies bovinas (RUEGG \& TABONE, 2000). Na Argentina são requeridos 500.000 células/ml (WEIDMANN et al., 1990).
Ainda, em rebanhos com controle sanitário satisfatório para mastite as contagens de células somáticas estão abaixo de 100.000 células $/ \mathrm{ml}$. Müller (2002) afirma que contagens de células somáticas maiores que 500.000 células $/ \mathrm{ml}$, indicam que um terço das glândulas mamárias estão infeccionadas e a perda de leite devido a mastite subclínica é de pelo menos $10 \%$.

Tabela 1. Estatística descritiva para características de composição físico-química do leite de fêmeas mestiças criadas em região de cerrado

\begin{tabular}{lccccc}
\hline Variável $^{1}$ & Média & DP & Máximo & Mínimo & $\mathrm{CV}^{2}$ \\
\hline CCS $\left(\right.$ células x $\left.10^{-3} / \mathrm{mL}\right)$ & 429,18 & 513,30 & $2.974,00$ & 1,00 & 119,60 \\
Gordura $(\mathrm{g} / 100 \mathrm{~g})$ & 3,52 & 0,80 & 5,60 & 1,58 & 22,72 \\
Proteína $(\mathrm{g} / 100 \mathrm{~g})$ & 3,13 & 0,26 & 3,87 & 2,45 & 8,31 \\
Lactose $(\mathrm{g} / 100 \mathrm{~g})$ & 4,48 & 0,23 & 4,97 & 3,75 & 5,13 \\
ESD $(\mathrm{g} / 100 \mathrm{~g})$ & 11,86 & 0,86 & 13,92 & 9,50 & 7,25 \\
\hline
\end{tabular}

${ }^{1} \mathrm{CCS}=$ contagem de células somáticas e ESD = extrato seco desengordurado; ${ }^{2} \mathrm{DP}=$ desvio padrão e $\mathrm{CV}=$ coeficiente de variação.

O efeito de fazenda $(\mathrm{p}=0,1499)$ não influenciou a probabilidade de ocorrência de mastite (Tabela 2). Isso pode ser explicado pela similaridade de manejo utilizado nas empresas avaliadas com uso de pastagens durante $\mathrm{o}$ verão $\mathrm{e}$ suplementação de concentrado durante a ordenha.

Os teores de proteína ( $\mathrm{p}=0,3057)$ e ESD $(\mathrm{p}=0,6565)$ não influenciaram a probabilidade de ocorrência de mastite (Tabela 2). Resultados similares foram descritos por Elias et al. (2005) e Zafalon et al. (2009). No entanto, Nielsen et al. (2005) e Pereira et al. (1999) afirmaram que o efeito de diluição, resultante da maior produção de leite nos animais sadios, pode resultar em maior conteúdo de proteína do leite em glandulas mamárias acometidas com mastite quando comparados a animais sadios.
O aumento do teor de proteína não deve ser considerado favorável à qualidade do leite, pois o leite de quartos mamários com mastite subclínica pode apresentar uma elevação nos níveis de soroproteínas pelo aumento da permeabilidade capilar e consequente passagem destas proteínas para os alvéolos. Dessa forma, na mastite subclínica o aumento do conteúdo de proteína total do leite é resultado do incremento da lactoferrina, de imunoglobulinas e da soroalbumina bovina, proteínas associadas com respostas inflamatórias da glândula mamária (URECH et al., 1999). Durante o processamento industrial do leite, estas proteínas são perdidas, enquanto a caseína, proteina de interesse no processo industrial da producao de queijos (GLANTZ et al., 2009), é diminuída pela ocorrência da mastite (PEREIRA et al., 1999). 
Tabela 2. Estimativa de parâmetros usados na modelagem da probabilidade de ocorrência de mastite em função da composição físico-química do leite de fêmeas mestiças criadas na região de cerrado

\begin{tabular}{lcccccccc}
\hline $\begin{array}{c}\text { Variável } \\
\text { Regressora }\end{array}$ & $\begin{array}{c}\text { Coeficiente de } \\
\text { regressão }\end{array}$ & $\begin{array}{c}\text { Razão entre } \\
\text { chances }\end{array}$ & $\begin{array}{c}\text { Intervalo de } \\
\text { confiança }\end{array}$ & \% pares & $\begin{array}{c}\text { Suc/I } \\
\text { ns }\end{array}$ & P \\
\hline CCS & $\hat{\beta}_{0}$ & $\hat{\beta}_{1}$ & Odds ratio & & Conc. & Disc. & & \\
Gordura & $-1,1985$ & 0,00403 & 1,004 & $1,003-1,005$ & 80,3 & 19,4 & $98 / 86$ & $<0,001$ \\
Proteína & $-1,3570$ & 0,4238 & 1,528 & $1,044-2,236$ & 58,5 & 40,8 & $98 / 86$ & $<0,029$ \\
lactose & $-1,6952$ & 0,5840 & 1,793 & $0,587-5,482$ & 52,4 & 46,1 & $98 / 86$ & 0,3057 \\
ESD & 15,20 & $-3,35$ & 0,035 & $0,007-0,166$ & 68,9 & 30,6 & $98 / 86$ & $<0,001$ \\
Fazenda & $-0,7825$ & 0,0770 & 1,080 & $0,769-1,516$ & 48,9 & 47,8 & $98 / 86$ & 0,6565 \\
& $-0,4524$ & 0,3211 & 1,379 & $0,891-2,135$ & 36,7 & 24,5 & $98 / 86$ & 0,1499 \\
\hline
\end{tabular}

${ }^{\mathrm{I}} \mathrm{CCS}=$ contagem de células somáticas em células $\times 10^{-3} / \mathrm{mL}$, gordura, proteína, lactose e ESD $=$ extrato seco desengordurado em $\mathrm{g} / 100 \mathrm{~g} ;{ }^{2}$ Conc. $=$ concordantes e Disc. $=$ discordantes.

O Governo e algumas indústrias beneficiadoras bonificam o produtor pelo leite com maior teor de proteína (ROMA JÚNIOR et al., 2009; CUNHA et al., 2010) tendo como beneficio melhora na qualidade do leite (BUENO et al., 2004). Portanto, estimular o pagamento de leite por qualidade no Norte de Minas Gerais em que os produtores são cotistas e recebem por volume de leite produzido e não por sólidos no leite, pode ser uma alternativa viável (SANTOS et al., 2008) que já é empregda com sucesso em outras regiões do país (BUENO et al., 2004).

Os teores de gordura $(p=0,0292)$ e lactose $(<0,001)$ influenciaram a probabilidade de ocorrência de mastite (Tabela 2). A odds ratio de 1,528 para gordura indicou que $\mathrm{o}$ aumento em uma unidade de gordura do leite $(\mathrm{g} / 100 \mathrm{~g})$ esta relacionada ao incremento de $52,8 \%$ na probabilidade de ocorrência de mastite. A possível redução na produção de leite total em fêmeas acometidas com mastite pode resultar em maior proporção de gordura. Entretanto, uma alternativa eficiente para aumentar o teor de gordura seria a utilização de uma dieta rica em fibras e gordura saturada (BUENO et al., 2005).

A odds ratio de 0,035 para lactose indicou que o aumento em uma unidade de lactose $(\mathrm{g} / 100 \mathrm{~g})$ esta relacionada a redução de 96,5\% na probabilidade de ocorrência de mastite (Tabela 2). Associações negativas entre lactose e infeção por mastite em bovinos também foram documentadas na literatura por Reis et al. (2013) e Gonçalves et al. (2016). A menor síntese de lactose pode ser ocasionada pela destruição de tecido secretor, também pela perda de lactose da glândula para a corrente sanguínea decorrente do aumento da permeabilidade da membrana que separa o leite do sangue e à utilização da lactose pelos patógenos intramamários nos animais positivos para mastite (ARAÚJO et al., 2011).

A CCS também influenciou a probabilidade de ocorrência de mastite $(\mathrm{p}<0,001)$ e a odds ratio de 1,004 indicou que o aumento em uma unidade de CCS (Células/ mL x 1000) está relacionada ao incremento de $0,4 \%$ na probabilidade da ocorrência de mastite (Tabela 2). Rangel et al. (2013) afirmaram que a CCS pode ser utilizada como parâmetro para indicar a prevalência de mastite nos rebanhos. Isso justifica a relação existente entre essas variáveis. Altos índices de CCS podem prejudicar a atividade enzimática, o tempo de coagulação, a produtividade e a qualidade e 
Rev. Bras. Saúde Prod. Anim., Salvador, v.17, n.4, p.642-651 out./dez., 2016 http://www.rbspa.ufba.br ISSN 15199940

rendimento dos derivados lácteos (BALLOU et al., 1995).

O padrão publicado pela Legislação Brasileira de limite inferior para proteína $2,90 \mathrm{~g} / 100 \mathrm{~g}$, ESD de $8,40 \mathrm{~g} / 100 \mathrm{~g}$, gordura de $3,0 \mathrm{~g} / 100 \mathrm{~g}$ e CCS de 600.000 células $/ \mathrm{mL}$ está relacionado ao incremento em $50 \%$, $46 \%, 48 \%$ e $28 \%$, respectivamente de probabilidade de ocorrência de mastite (Figura 1). Dessa forma, podem ser delineadas e propagadas ações que garantam à segurança alimentar e informem sobre efeitos dessa incidência de mastite nos rebanhos sobre a saúde humana, meio ambiente e bem-estar animal, sanidade e qualidade dos alimentos produzidos. Sendo de fundamental importância nesse processo monitorar, controlar e, eventualmente, melhorar a qualidade composicional, higiênica, nutricional, sensorial e tecnológica do leite cru (VALFRÈ \& MORETTI, 1997).
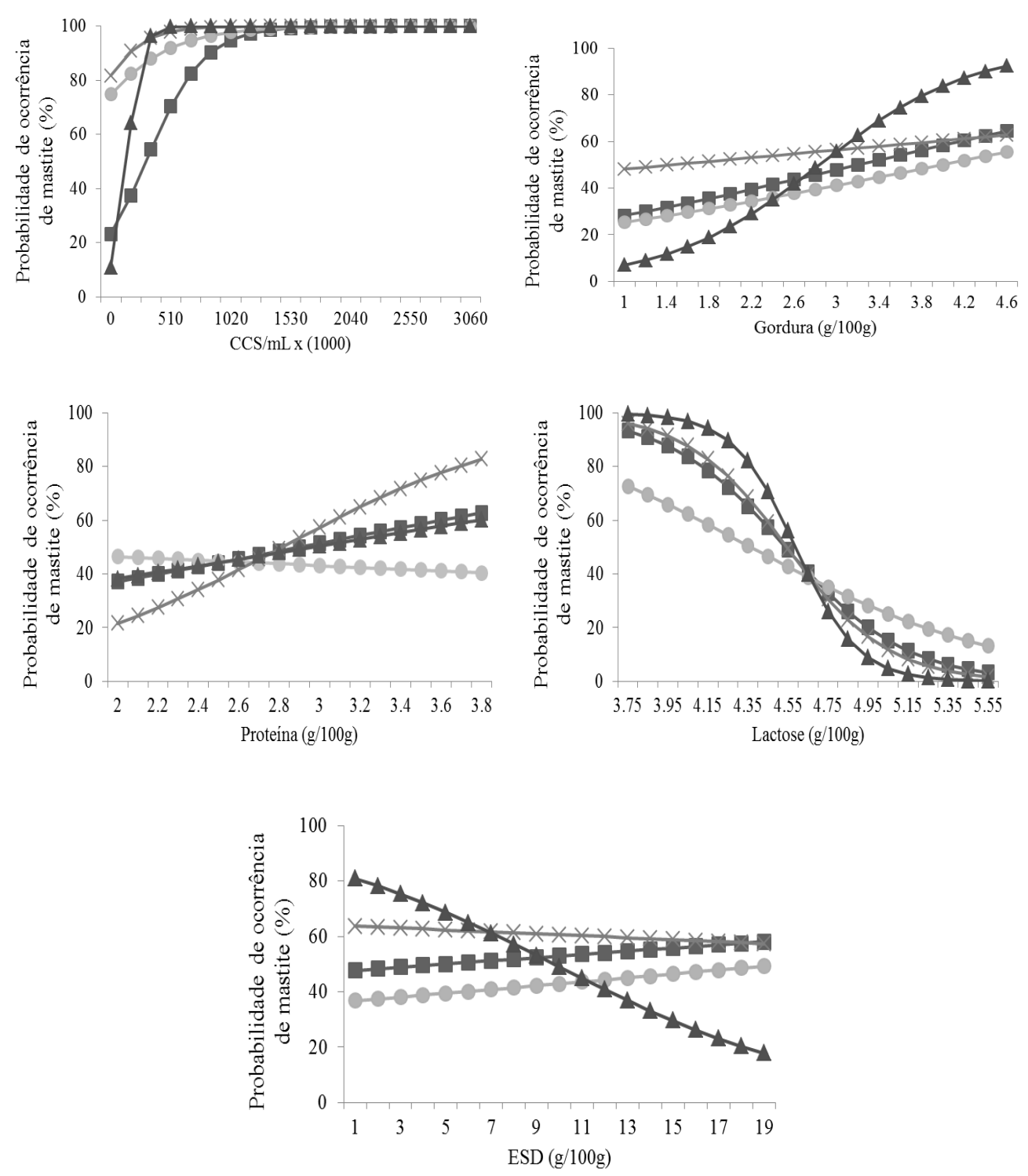

-MédiaGeral —Fazenda $1 \multimap$ Fazenda $2 \multimap$ Fazenda 3

Figura 1. Probabilidade de ocorrência de mastite de acordo com o teor de proteína, ESD, gordura, lactose e CCS para a média geral e em cada fazenda avaliada 
Rev. Bras. Saúde Prod. Anim., Salvador, v.17, n.4, p.642-651 out./dez., 2016 http://www.rbspa.ufba.br ISSN 15199940

Vallin et. al. (2009) afirmaram que boas praticas de higiene na ordenha como o desprezo dos três primeiros jatos de leite, limpeza e desinfeção das instalações, tanque de expansão, utensílios e equipamentos da ordenha, realização do pré e pós dipping com solução clorada $750 \mathrm{ppm}$ em caneca sem refluxo e linha de ordenha podem reduzir a incidência de mastite e aumentar a disponibilidade de leite, com composição físico-química adequada, para os demais setores da cadeia produtiva do leite.

Por meio de modelos de regressão logística é possível quantificar a relação entre contagem de célula somática, teores de gordura e lactose e probabilidade de ocorrência de mastite. A contagem de células somáticas é a variável de maior impacto sobre a probabilidade de ocorrência de mastite.

\section{AGRADECIMENTOS}

As Fazendas Pedra Preta, Poções e Veados Santa Eliza pela disponibilização dos dados, à Capes, CNPq, FAPEMIG e Universidade Federal de Minas Gerais pelo apoio financeiro.

\section{REFERÊNCIAS}

ARAÚJO, P.M.; PAULO, J.L.A.; PEREIRA, G.F.; FONSECA, F.C.E.; RANGEL, A.H.N. Análise físicoquimica do leite de um rebanho gir na região litorânea do Rio Grande do Norte.

Revista Verde, v.6, n.3, p.120-124, 2011.

BALLOU, L.U.; PASQUINI, M.; BREMEL, R.D.; EVERSON, T.; DEAN OMME, R.D. Factors affecting herd milk composition and milk plasmin at four levels of somatic cell counts. Journal of Dairy Science, v.78, p.2186-2195, 1995.
BENTLEY INSTRUMENTS INC. Somacount 300 Operator's Manual. Chaska: Bentley Instruments Inc.; 1997. $116 \mathrm{p}$.

BERGMANN, J.A.G.; HOHENBOKEN, W.D. Prediction of fertility from calfhood traits of Angus and Simenthal heifers. Journal of Animal Science, v.70, p.2611-2621, 1992.

BUENO, P.R.B.; RORATO, P.R.N.; DÜRR, J.W.; KRUG, E.E.B. Valor econômico para componentes do leite no estado do Rio Grande do Sul. Revista Brasileira de Zootecnia, v.33, n.6, p.2256-2265, 2004.

BUENO, V.F.F.; MESQUITA, A.J.; NICOLAU, E.S.; OLIVEIRA, A.N.; OLIVEIRA, J.P.; NEVES, R.B.S.; MANSUR, J.R.G.; THOMAZ, L.W. Contagem celular somática: relação com a composição centesimal do leite e período do ano no Estado de Goiás. Ciência Rural, v.35, n.4, p.848-854, 2005.

CUNHA, D.N.F.V.; PEREIRA, J.C.; CAMPOS, O.F.; GOMES, S.T.; BRAGA, J.L.; MARTUSCELLO, J. A. Simulation of Holstein and Jersey profitability by varying milk price payment system. Revista Brasileira de Zootecnia, v.39, n.4, p.913-923, 2010.

CUNHA, A.F.; PARREIRA, D.S.; SILVA, S.Q.; OLIVEIRA, M.M.; CERQUEIRA, P. Efeitos do treinamento de transportadores de leite na determinação da qualidade do leite cru refrigerado. Acta Veterinaria Brasilica, v.7, n.3, p.241-246, 2013.

DEZETTER, C.; LECLERC, H.; MATTALIA, H.; BARBAT, H.; BOICHARD' D.; DUCROCQ, V. Inbreeding and crossbreeding parameters for production and fertility traits in 
Rev. Bras. Saúde Prod. Anim., Salvador, v.17, n.4, p.642-651 out./dez., 2016 http://www.rbspa.ufba.br ISSN 15199940

Holstein, Montbéliarde, and Normande cows. Journal of Dairy Science, v.98, n.7, p.4904-4913, 2015.

ELIAS, A.O.; VICTORIA, C.; SILVA, A.V.; LANGONI, H. Características físico-químicas e contagem de células somáticas de leite proveniente de vacas naturalmente infectadas por Streptococcus spp. Arquivos de Ciências Veterinárias e Zoologia da UNIPAR, v.8, n.2, p.165-170, 2005.

FERREIRA, J.L.; LINS, J.L.F.H.A.; CAVALCANT, T.V.; MACEDO, N.A.; BORJAS, A.R. Prevalência e etiologia da mastite bovina no município de Teresina, Piauí. Ciência Animal Brasileira, v.8, n.2, p.261-266, 2007.

FREUND, R.J.; LITTELL, R.C. SAS ${ }^{\circledR}$ System for Regression. $3^{\text {rd }}$. Cary, NC: SAS Institute Inc, 2000.235p.

GLANTZ, M.; MANSSON, H.L.; STALHAMMAR, H.; BARSTRÖM, L.O.; FRÖJELIN, F.M.; KNUTSSON, A.; TELUK, C.; PAULSSON, M. Effects of animal selection on milk composition and processability. Journal of Dairy Science, v.92, n.9, p.4589-4603, 2009.

GONÇALVES, J.L; TOMAZI, T.; BARREIRO, J.R.; ARCARI, M.A.; LEE, S.H.I.; MARTINS, C.M.M.R.; ARAÚJO JUNIOR, J.P.; SANTOS, M.V. Effects of bovine subclinical mastitis caused byCorynebacterium spp. on somatic cell count, milk yield and composition by comparing contralateral quarters.

Journal of Dairy Science, v.209, p. 8792, 2016.

INTERNATIONAL DAIRY FEDERATION. Milk: enumeration of somatic cell. IDF Standard 148A. Brussels: IDF, 1995. 8p.
MELLO, C.R.; SÁ, M.A.C.; CURI, N.; MELLO, J.M.; VIOLA, M.R.; SILVA, A.M. Erosividade mensal e anual da chuva no Estado de Minas Gerais. Pesquisa Agropecuária Brasileira, v.42, n.4, p.537-545, 2007.

MÜLLER, E.E. Qualidade do leite, células somáticas e prevenção da mastite. In: II SUL-LEITE: SIMPÓSIO SOBRE SUSTENTABILIDADE DA PECUÁRIA LEITEIRA NA REGIÃO SUL DO BRASIL, 2002, Maringá. Anais... Maringá: UEM, 2002. p.206217.

NIELSEN, N.I.; LARSEN, T.; BJERRING, M.; INGVARTSEN, K.L. Quarter health, milking interval, and sampling time during milking affect the concentration of milk constituents.

Journal of Dairy Science, v.88, n.9, p.3186-3200, 2005.

PHILPOT, W.N.; NICKERSON, S.C. Mastitis counter attack: A strategy to combat mastitis. Naperville: Babson Bros, 1991. 150p.

PEREIRA, A.R.; PRADA e SILVA, L.F.; MOLON, L.K.; MACHADO, P.F.; BARANCELLI, G. Efeito do nível de células somáticas sobre os constituintes do leite I-gordura e proteína. Brazilian Journal of Veterinary Research and Animal Science, v.36, n.3, p.121-124, 1999.

RADOSTITS, O.M.; GAY, C.C.; BLOOD, D.C.; HINCHCLIFF, K.W. Clínica Veterinária: um tratado de doenças dos bovinos, ovinos, suínos, caprinos e eqüinos. 9.ed. Rio de Janeiro: Guanabara Koogan, 2002. 1737p.

RANGEL, A.H.N.; ARAÚJO, V.M.; BEZERRA, K.C.; BARRETO, M.L.J.; MEDEIROS, H.R.; LIMA JUNIOR, D.M. Avaliação da qualidade do leite cru com 
Rev. Bras. Saúde Prod. Anim., Salvador, v.17, n.4, p.642-651 out./dez., 2016 http://www.rbspa.ufba.br ISSN 15199940

base na contagem de células somáticas em rebanhos bovinos comerciais no estado do Rio Grande do Norte, Brasil. Archives of Veterinary Science, v.18, n.1, p.40-45, 2013.

REIS, C.B.M; BARREIRO, J.R.; MESTIERI, L.; PORCIONATO, M.A.F.; SANTOS, M.V. Effect of somatic cell count and mastitis pathogens on milk composition in Gyr cows. BMC

Veterinary Research, v.9, p.67, 2013.

ROMA JÚNIOR, L.C.; MONTOYA, J.F.G.; MARTINS, T.T.; CASSOLI, L.D.; MACHADO, P.F. Sazonalidade do teor de proteína e outros componentes do leite e sua relação com programa de pagamento por qualidade. Arquivo Brasileiro de Medicina Veterinária e Zootecnia, v.61, n.6, p.1411-1418, 2009.

RUEGG, P.L.; TABONE, T.J. The relationship between antibiotic residue violations and somatic cell counts Wisconsin dairy herds. Journal of Dairy Science, v.83, p.2805-2809, 2000

SANTOS, C.A.; MENEZES, I.R.; VIEIRA, V.A.; SILVA, B.C.M.; TEIXEIRA, L.M.; ALMEIDA, A.C. Manejo nutricional adotado para vacas em lactação no Norte de Minas. A produção de leite no Norte de Minas: diagnóstico e 129 propostas para melhorias. In: II ENCONTRO DE PRODUTORES DE LEITE NO NORTE DE MINAS, 2008, Montes Claros. Anais... Montes Claros: UFMG, 2008.

SCABIN, K.E.M.; KOZUSNYANDREANI, D.I.; FRIAS, D.F.R. Microbiological quality of milk in nature during the process of obtaining and after cooling. Revista CES Medicina Veterinaria y Zootecnia, v.7, n.1, p.1121, 2012.
VALLIN, V.M.; BELOTI, V.; BATTAGLINI, A.P.P.; TAMANINI, R.; FAGNANI, R.; ANGELA, H.L.; SILVA, L.C.C. Melhoria da qualidade do leite a partir da implantação de boas práticas de higiene na ordenha em 19 municípios da região central do Paraná. Ciências Agrárias, v.30, n.1, p.181-188, 2009.

VALFRE, F.; MORETTI, V.M. Characteristics, quality and control of animal products for human consumption. In: BOYAZOGLU, J.; RENAUD, J. (Ed.). The livestock production sector in Eastern Europe as affected by current changes. Wageningen, Holanda: EAAP Publication, 1997. n.57, p.144-148.

VLIEGHER, S.; FOX, L.K.; PIEPERS, S.; MCDOUGALL, S.; BARKEMA, H.W. Mastitis in dairy heifers: Nature of the disease, potential impact, prevention, and control. Journal of Dairy Science, v.95, n.3, p.1025-1040, 2012.

URECH, E.; PUHAN, Z.; SCHALLIBAUM, M. Changes in milk protein fraction as affected by subclinical mastitis. Journal of Dairy Science, v.82, n.11, p.2402-2411, 1999.

WEIDMANN, P.; HEER, G.; ROSSET, A.; GONZÁLES, A.; WEIDMANN, R.; ERNI, L.; RUSSI, N. Calidad de la leche producida en 25 tambos que aplicaban tecnología avanzada en el Departamento Las Colonias, Provincia de Santa Fe. Revista Argentina de Producción Animal, v.8, supl. 1, p.134-135, 1990.

ZAFALON, L.F.; NADER FILHO, A.; CARVALHO, M.R.B.; LIMA, T.M.A. Mastite subclinica bovina: teores de proteínas no leite após o tratamento durante a lactação. Arquivos do Instituto

Biológico, v.76, n.2, p.149-155, 2009.

Data de recebimento: $15 / 02 / 2016$

Data de aprovação: 23/08/2016 